\title{
The Operative Risk Factors in the Metabolic Syndrome: Is It Lipids and High BP or Are There Direct Vascular Effects of Insulin Resistance and Obesity?
}

\author{
Fabrice M.A.C. Martens, $M D, P h D$, and Frank L.J. Visseren, $M D, P h D$
}

\author{
Corresponding author \\ Fabrice M.A.C. Martens, MD, PhD \\ Department of Cardiology, St. Antonius Hospital, Koekoekslaan 1, \\ PO Box 2500, 3430 EM, The Netherlands. \\ E-mail: f.martens@antonius.net
}

Current Diabetes Reports 2007, 7:74-81

Current Medicine Group LLC ISSN 1534-4827

Copyright $\odot 2007$ by Current Medicine Group LLC

Increase in patients with central obesity and insulin resistance is an important cause for the worldwide increased incidence of type 2 diabetes. Several risk factors such as glucose intolerance, hyperinsulinemia, obesity, dyslipidemia, and hypertension, but also endothelial dysfunction and inflammation, have been found to cluster and often precede type 2 diabetes mellitus. Seeing the importance of early identification, the US National Cholesterol Education Program created a readily applicable definition of the metabolic syndrome for daily clinical practice. It is assumed that the cardiovascular risk for patients belonging to the metabolic syndrome can just be calculated out of the sum of the separate cardiovascular risk factors dyslipidemia and hypertension. However, there are also data pointing toward a higher risk than expected from these separate cardiovascular risk factors because of possible direct vascular effects of insulin resistance and obesity. Awareness of the underlying disorders of insulin resistance and its associated (non-) traditional risk factors such as endothelial dysfunction and inflammation is important for understanding the pathophysiology and thus coherent treatment.

\section{Introduction}

The metabolic syndrome has received increasing attention over the past few years and is a subject of debate. The metabolic syndrome is conceptualized as a constellation of interrelated cardiovascular risk factors of metabolic origin that appear to directly promote the development of atherosclerotic cardiovascular disease (CVD) and increase the risk for developing type 2 diabetes mellitus. The prevalence of type 2 diabetes has soared in the past decades because of changing lifestyle and eating habits; there are currently approximately 200 million people affected worldwide. Insulin resistance as a consequence of (abdominal) obesity (with approximately 400 million people affected worldwide right now) is one of the main underlying causes of the increased incidence of type 2 diabetes.

The major long-term complications of type 2 diabetes are an increased risk of myocardial infarction, stroke, and peripheral vascular disease. Although microvascular complications cause considerable morbidity in patients with type 2 diabetes, up to $80 \%$ of patients die from macrovascular pathology [1]. Treatment of individual risk factors has been shown to reduce cardiovascular events in type 2 diabetes. Dysglycemia does not appear to be the major determinant of CVD in type 2 diabetes, a concept supported by observations in the UKPDS (United Kingdom Prospective Diabetes Study) [2]. Individuals or patients with impaired glucose tolerance and/or impaired fasting glucose are so-called prediabetic and are at risk for developing type 2 diabetes [3]. Treatment (with lifestyle recommendations and medication) as primary prevention of these individuals or patients can substantially reduce

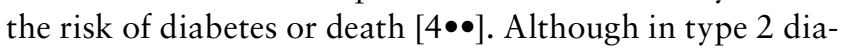
betes elevated plasma glucose concentrations may induce vascular damage, in prediabetic patients the increased cardiovascular risk is most likely the result of the pathophysiologic phenomenon of insulin resistance, which leads to the occurrence of classic risk factors (eg, elevated blood pressure, low high-density lipoprotein [HDL] cholesterol, elevated triglycerides) and new risk factors such as inflammation, hypercoagulability, hypoadiponectinemia, and impaired vasoreactivity [5]. 


\begin{tabular}{l} 
Table 1 . Most used definition of the \\
metabolic syndrome \\
\hline Combination of 3 or more of the following parameters: \\
Fasting glucose $\geq 6.1 \mathrm{mmol} / \mathrm{L}$ and/or medication \\
Central obesity in terms of a waist $>102 \mathrm{~cm}$ for males \\
and $>88 \mathrm{~cm}$ for females \\
Triglycerides $\geq 1.7 \mathrm{mmol} / \mathrm{L}$; or specific treatment \\
$\mathrm{HDL}<1.04 \mathrm{mmol} / \mathrm{L}$ for males and $<1.29 \mathrm{mmol} / \mathrm{L}$ for \\
females; or specific treatment \\
Blood pressure $\geq 130 / 85 \mathrm{~mm} \mathrm{Hg}$ and/or medication \\
HDL-high-density lipoprotein. \\
(From the National Cholesterol Education Program Adult \\
Treatment Panel III [8].)
\end{tabular}

\section{The Term "Metabolic Syndrome"}

Many studies confirm that multiple cardiovascular risk factors of endogenous origin commonly aggregate in one individual. Several terms have been proposed to describe this clustering, but the term "metabolic syndrome" is most commonly used in the cardiovascular field. It is important to recognize that the metabolic syndrome is not a defined uniform entity. No clear pathogenesis has been elucidated and may not exist. The concept of the syndrome could range from a cluster of (un-) related risk factors to a constellation of risk factors linked through a common underlying mechanism.

\section{Definitions of the Metabolic Syndrome}

That the pathogenesis is not clear yet is shown in the different definitions several organizations have attempted to formulate in the effort to introduce the metabolic syndrome into clinical practice. All definitions include a measure of blood pressure, triglycerides, HDL cholesterol, and fasting glucose. They differ with respect to the selection of cutoff points and a measure of obesity.

\section{NCEP}

In contrast to the World Health Organization (WHO) and the European Group for Study of Insulin Resistance (EGIR) definitions, in which the presence of hyperinsulinemia as an indicator of insulin resistance is the starting point, the National Cholesterol Education Program (NCEP) definition is based on the number of abnormalities only, whereas the American Association of Clinical Endocrinologists (AACE) definition considers the number of abnormalities in selected subjects with high risk of insulin resistance. The latest International Diabetes Federation (IDF) definition considers abdominal obesity as the pathogenetic starting point.

\section{WHO}

In 1998, the WHO proposed the first definition, which emphasized that insulin resistance is the major underlying risk factor and required evidence of insulin resistance for diagnosis: impaired glucose tolerance, impaired fasting glucose, type 2 diabetes mellitus, or impaired disposal of glucose as measured by hyperinsulinemic-euglycemic clamping. The other risk factors used for diagnosis included obesity, hypertension, high triglycerides, reduced HDL cholesterol level, or microalbuminuria [6].

\section{EGIR}

In 1999, the EGIR proposed a modification of the WHO definition by assuming that insulin resistance is the major cause and required evidence of hyperinsulinemia. Next to an elevated plasma insulin, microalbuminuria was replaced by an elevated plasma glucose to diagnose the insulin resistance syndrome. Patients with type 2 diabetes were excluded because insulin resistance was viewed primarily as a risk factor for diabetes [7].

\section{New definition by NCEP}

For practical reasons, a new definition was introduced in 2001 by the NCEP: the Adult Treatment Panel III (ATP III) criteria [8]. According to this definition, the metabolic syndrome can be diagnosed if at least three out of the following five (metabolic) abnormalities are present: elevated fasting glucose levels, elevated blood pressure, low plasma HDL cholesterol levels, elevated plasma triglycerides, and central obesity. Because the obligatory presence of insulin resistance is abandoned, this definition is easy to use for daily clinical practice.

\section{AACE}

In 2003, the AACE modified the ATP III criteria to refocus on insulin resistance as the primary cause of metabolic risk factors [9]. Major criteria were impaired glucose tolerance, elevated triglycerides, reduced HDL cholesterol, elevated blood pressure, and obesity.

\section{IDF}

In 2005, a new definition for the metabolic syndrome was introduced by the IDF. Based on the obligatory presence of an increased waist circumference, it paid attention to the elementary role of abdominal obesity in the development of the metabolic syndrome (Table 1) [10].

\section{Prevalence of the Metabolic Syndrome and Risk for Cardiovascular Events}

It is estimated that approximately one fifth of the US population has the metabolic syndrome, and prevalence increases with age. The prevalence of the metabolic syndrome in a healthy American population is approximately $24 \%$ [11]. In Europe, the prevalence seems similar, approximately $20 \%$, with a difference between women $(12 \%)$ and men $(23 \%)[12,13]$. In patients with clinical manifestations of vascular disease, the prevalence is $45 \%$; and in patients with type 2 diabetes mellitus the prevalence is $80 \%$ [14]. Alternative definitions of the metabolic syndrome highly predict type 2 diabetes mellitus [15]. 
Although different definitions have been used in various studies, in most studies a similar increased risk of CVD of approximately twofold is found in patients with the metabolic syndrome compared to those without the metabolic syndrome [16-22,23•]. Associations between metabolic syndrome definitions and the risk of CVD ranged between 1.5 for fatal and nonfatal myocardial infarction or stroke for the NCEP definition in high-risk subjects with elevated cholesterol [20], and 3.7 for fatal and nonfatal coronary disease for the WHO definition in the general Italian population [24]. In addition, the metabolic syndrome is associated with advanced vascular damage in patients with coronary heart disease, stroke, peripheral arterial disease or abdominal aortic aneurysm [25], and untreated essential hypertension [26]. However, the ATP III but not the IDF criteria of the metabolic syndrome predict clinical cardiovascular events in subjects who underwent coronary angiography $[27 \bullet \bullet]$.

The enormous number of people at risk for CVD and type 2 diabetes is about to increase dramatically because of the global increase in abdominal obesity [28].

Is It Dyslipidemia and High BP That Cause the Elevated Risk for Cardiovascular Events in the Metabolic Syndrome or Are There Direct Vascular Effects of Insulin Resistance and Obesity?

It is assumed that the cardiovascular risk for patients with the metabolic syndrome can be explained by the sum of the separate cardiovascular risk factors. However, there are also suggestions that the risk for developing CVD is more than just the sum of the separate cardiovascular risk factors [29•]. Moreover, the increased cardiovascular risk for patients with the metabolic syndrome cannot be completely explained by the traditional models for risk scoring, such as the Framingham score $[20,30]$. This increased cardiovascular risk may be due to the combination of nontraditional markers, which all have a relation with insulin resistance, together with the separate traditional components of the metabolic syndrome (hyperglycemia, hypertension, low plasma HDL cholesterol, high plasma triglyceride levels, and obesity). The nontraditional markers are endothelial dysfunction, inflammation, hyperinsulinemia, oxidative stress, hypercoagulability together with decreased fibrinolysis, decreased adiponectin levels, and increased small-dense low-density lipoprotein (LDL) [31-34].

Insulin Resistance and the Pathophysiology Behind the Clustered Risk Factors in Association with Central Obesity

Insulin is the most important regulator for the plasma glucose level. It works by stimulating the disposal of glucose in skeletal muscle and adipose tissue and decreasing the hepatic glucose production. Furthermore, insulin stimulates the lipogenesis and glycogen- and protein-synthase activity in adipocytes, liver, and skeletal muscle, and inhibits glycogenolysis, lipolysis, and protein breakdown (Fig. 1). In addition, insulin plays a role in the regulation of cell growth and differentiation.

Insulin resistance means that when insulin binds to the insulin receptor on the cell surface, this stimulation is not strong enough to induce the normal intracellular signal transduction with the consequence of insufficient reaction of target organs on insulin binding to the insulin receptor. In case of a sufficient pancreatic $\beta$-cell function, insulin resistance will lead to a compensatory hyperinsulinemia to maintain normoglycemia. Hyperglycemia follows by further increasing insulin resistance and after failure of the pancreatic $\beta$-cell function. Hyperinsulinemia has several important consequences as to cardiovascular risk, as described next.

\section{Adipose tissue}

Adipose tissue, especially intra-abdominal obesity, plays an important role in insulin resistance. In the INTERHEART study, abdominal obesity accounted for $44 \%$ of the risk of

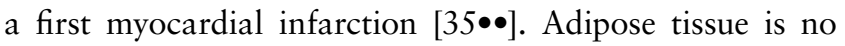
longer only a depot, but can be seen as an endocrine organ [36]. Several products of adipose tissue may influence development of insulin resistance. Important adipocyte-derived factors are free fatty acids (FFAs), tumor necrosis factor- $\alpha$ (TNF- $\alpha$ ), adiponectin, and leptin. High levels of FFAs have been linked to (the induction of) insulin resistance because increased FFA production in the liver leads to increased gluconeogenesis and decreased glucose metabolism in skeletal muscle [37]. Furthermore, high levels of FFAs will lead to an increase of very low density lipoprotein (VLDL), together with an increase of plasma triglycerides [38]. In an insulin-resistant state there is an attenuated lipoprotein lipase activity. Lipoprotein lipase is involved in the lipolysis of VLDL. Decreased breakdown of VLDL particles leads to reduced availability of small VLDL fragments and an increase in triglyceride-rich HDL particles via cholesterol ester transfer protein. Triglyceride-rich HDL particles are cleared faster by the liver, resulting in a decreased HDL plasma concentration and an increased triglyceride concentration [39]. The expression of TNF- $\alpha$ by adipose tissue is upregulated in obesity and TNF- $\alpha$ levels are increased in patients with features of the insulin resistance syndrome (ie, endothelial dysfunction), inducing a higher risk of recurrent coronary events [40-42]. Adiponectin is an adipocytederived hormone that decreases insulin resistance. A low adiponectin plasma concentration precedes a decrease in whole-body insulin sensitivity in humans $[34,43,44]$. The role of leptin in insulin resistance is controversial, but leptin might interfere with insulin signaling in certain cell types.

\section{Hypertension}

Hyperinsulinemia also causes hypertension. Normally insulin has a vasodilating effect; however, in an insulin- 


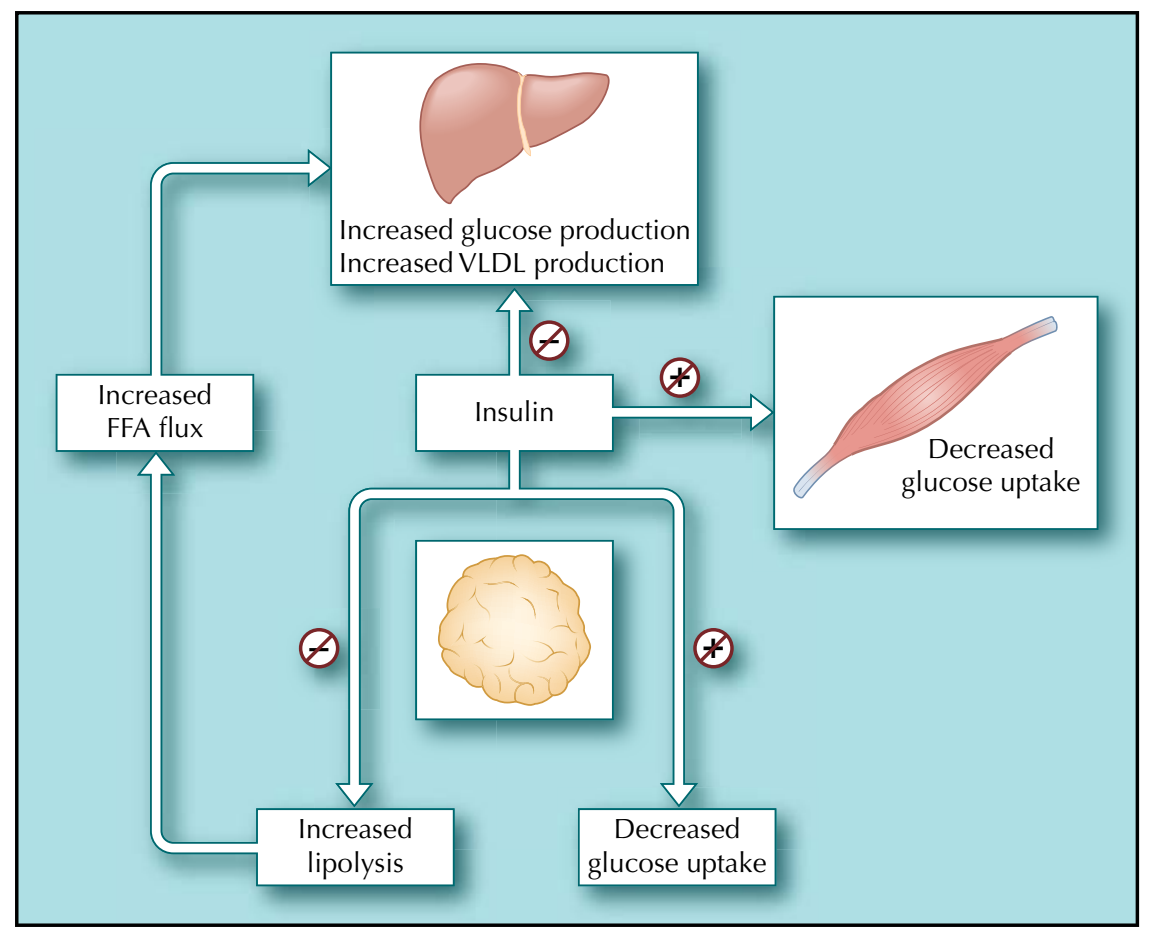

Figure 1. Pathophysiology of insulin resistance. FFA — free fatty acids; VLDL—very low density lipoprotein.

resistant state, insulin can cause sympathetic activation, production of the vasoconstrictor endothelin-1, and increase of renal salt retention. Together with, or leading to, endothelial dysfunction, leading to increased arterial resistance in the peripheral vasculature, these mechanisms can result in elevated blood pressure [45]. Several studies showed a relation between hyperinsulinemia, increased plasma FFA levels, and more oxidized smalldense LDL with endothelial dysfunction [46-48]. The Framingham study showed that abdominal obesity is the main hypertensinogenic factor [49]. A direct association between hypertension and body mass index has been observed in cross-sectional and longitudinal population studies from early childhood to old age [50]. The mechanism by which obesity raises blood pressure is not fully understood, but increased body mass index is associated with an increase in plasma volume and cardiac output. These alterations and blood pressure can be decreased by weight loss in both normotensive and hypertensive subjects. Furthermore, blood pressure in obese adolescents is sodium-sensitive, and fasting insulin is the best predictor of this sensitivity; after weight loss the blood pressure decreases and the salt sensitivity is reduced [51]. The variables that best predict sodium sensitivity are fasting plasma insulin, plasma aldosterone, and plasma norepinephrine, supporting the hypothesis that blood pressure is sensitive to dietary sodium and that this sensitivity may be due to the combined effect of hyperinsulinemia, hyperaldosteronism, and increased activity of the sympathetic nervous system [52]. Hyperinsulinemia increases both sympathetic nerve activity and sodium and water retention. The expected vasodilation, upon binding of insulin to the endothelial insulin receptor and causing activation of endothelial nitric oxide synthase, is impaired in insulin-resistant states [53]. It is also the heterogeneous effect of endogenous nitric oxide on proliferation along the vascular tree that relates to the two different phenomenons of insulin-resistant vascular dysfunction. Endothelial dysfunction exists in conduit arteries, whereas elevated vascular resistance of resistance arteries is observed in essential hypertension $[54,55]$.

\section{Enhanced low-grade inflammation}

Enhanced low-grade inflammation induces endothelial dysfunction by increased production of cytokines such as Creactive protein (CRP), TNF- $\alpha$, and interleukin-6 [56-58]. In addition, increased high-sensitivity CRP is associated with obesity, insulin resistance, and endothelial dysfunction. The more components of the metabolic syndrome that are present in the same person, the higher the plasma CRP concentration [59]. It is noteworthy that CRP not only seems to function as an indicator for CVD, but CRP may also play a role as a risk factor in atherogenesis [60].

\section{Discussion}

The metabolic syndrome as an independent cardiovascular risk factor

Currently, a critical discussion is ongoing concerning the role of the metabolic syndrome in (cardiovascular) risk prediction [61]. The additive value of using the metabolic syndrome in the prediction of future cardiovascular risk compared with various alternative risk-score algorithms is not fully clear yet. From a clinical standpoint, presence of the metabolic syndrome identifies a person at increased risk of CVD and/or type 2 diabetes. Eventually, a better 
understanding of the specific cause(s) of the syndrome may contribute to improved risk estimation for the development of CVD and/or type 2 diabetes. For now, the presence of the syndrome is a more general indicator of higher risk for developing CVD and/or type 2 diabetes and may also give insight into the pathophysiology behind the occurrence of individual risk factors. This knowledge may lead to better treatment of risk factors.

The observation that cardiovascular risk factors tend to cluster in individual patients is intriguing and has triggered basic and clinical researchers trying to understand and unravel the underlying pathophysiologic mechanisms behind this clustering. It is now generally accepted that insulin resistance plays an important and central role. The abdominal adipose tissue can be regarded as an organ with important endocrinologic functions, by the production of adipokines and cytokines, involved in energy homeostasis, inflammation, and fibrinolysis. In case of adiposity, the production of several inflammatory cytokines such as TNF- $\alpha$, leptin, and interleukin- 6 is increased, whereas the production of adiponectin is diminished. This alteration of adipokines is not only due to the excess of adipose tissue. Also, adipocyte dysfunction by itself contributes to the metabolic changes, which can be seen as a cause or a consequence of insulin resistance.

\section{Treatment of the metabolic syndrome}

Treatment of the metabolic syndrome has also been a topic of debate. It is assumed that the cardiovascular risk for patients with the metabolic syndrome can be calculated out of the sum of the separate cardiovascular risk factors. In the TNT (Treating to New Targets) study, univariate analysis of the individual characteristics of the metabolic syndrome showed a significant increased risk of major cardiovascular events with the presence of each component of the metabolic syndrome. Furthermore, the risk of major cardiovascular events increased with the presence of each additional component of the metabolic syndrome. Interestingly, patients with coronary heart disease and the metabolic syndrome benefited from aggressive atorvastatin therapy, irrespective of the presence of diabetes [62・•].

However, there are also data pointing toward a higher risk than could be expected from the separate cardiovascular risk factors (high triglycerides, low HDL, hyperglycemia, and high blood pressure) in relation to the metabolic syndrome. Treatment of these risk factors decreases the risk for cardiovascular events. Following this reasoning, reducing insulin resistance may further reduce the cardiovascular risk. New treatment strategies and pharmacologic treatments need to be evaluated in this respect. In addition, insulin resistance leads to hypertension, hypertriglyceridemia, low HDL, smalldense LDL, diminished fibrinolysis, and increased thrombogenicity. Because dysglycemia does not appear to be the major determinant of CVD in type 2 diabetes, targeting the underlying pathophysiologic mechanisms of the insulin resistance syndrome may be a more logical and beneficial strategy for reduction of cardiovascular morbidity and mortality. Although it is difficult to distinguish between the relative effects of insulin resistance, it induces a significantly increased cardiovascular and cerebrovascular risk. This effect is consistent across the spectrum of worsening glycemic control, from the onset of impaired glucose tolerance to the development of clinical diabetes. From a pathophysiologic point of view, treatment should be focused on reducing insulin resistance, which can be achieved by weight reduction and an increase in physical activity. By decreasing insulin resistance, improvement of both the individual components of the metabolic syndrome (hyperglycemia, elevated blood pressure, decreased HDL cholesterol, elevated triglycerides, and central obesity) and the nonclassical associated risk factors (impaired fibrinolysis, oxidative stress, increased small dense LDL cholesterol, hypercoagulability, inflammation, hyperinsulinemia, and decreased adiponectin levels) could be expected. Reduction of insulin resistance not only reduces the risk for cardiovascular events, but could also prevent or delay the development of type 2 diabetes in patients at increased risk $[63,64]$. The very recently published DREAM (Diabetes Reduction Assessment with Ramipril and Rosiglitazone Medication) trial is the first study investigating the effects of lifestyle interventions and medication on clinical end points in patients diagnosed with the metabolic syndrome; it showed a reduction of the risk of diabetes or death by $60 \%$ in individuals at high risk for diabetes $[4 \bullet \bullet]$. This very promising result is stimulating for more studies with peroxisome proliferator-activated receptor- $\gamma$ agonists, blockers of the endocannabinoid system, and therapeutic modulation of low adiponectin levels, all of which improve insulin sensitivity and influence the endocrine functions of the adipocyte, to investigate if treatment of patients with the metabolic syndrome without diabetes can be useful yet.

Although a pathophysiologic construct seems plausible, future research must unravel pathophysiology and clinical use before the metabolic syndrome can be designated as a "syndrome" useful in daily clinical practice [65••]. The question of whether the cardiovascular risk associated with the metabolic syndrome is more than the sum of the risk caused by its parts is not answered and may never be answered. The only way to resolve this issue would be with a follow-up study investigating the hazards on cardiovascular morbidity and mortality for each individual component, whereby during the follow-up period no other risk factors develop and no treatment occurs.

It is certain that the individual components (eg, dyslipidemia and hypertension) that make up the syndrome should be treated together. These are "the visible mountains of the floating iceberg above the water." However, there are other risk factors (ie, the direct vascular effects of insulin resistance and obesity) "underneath the water 


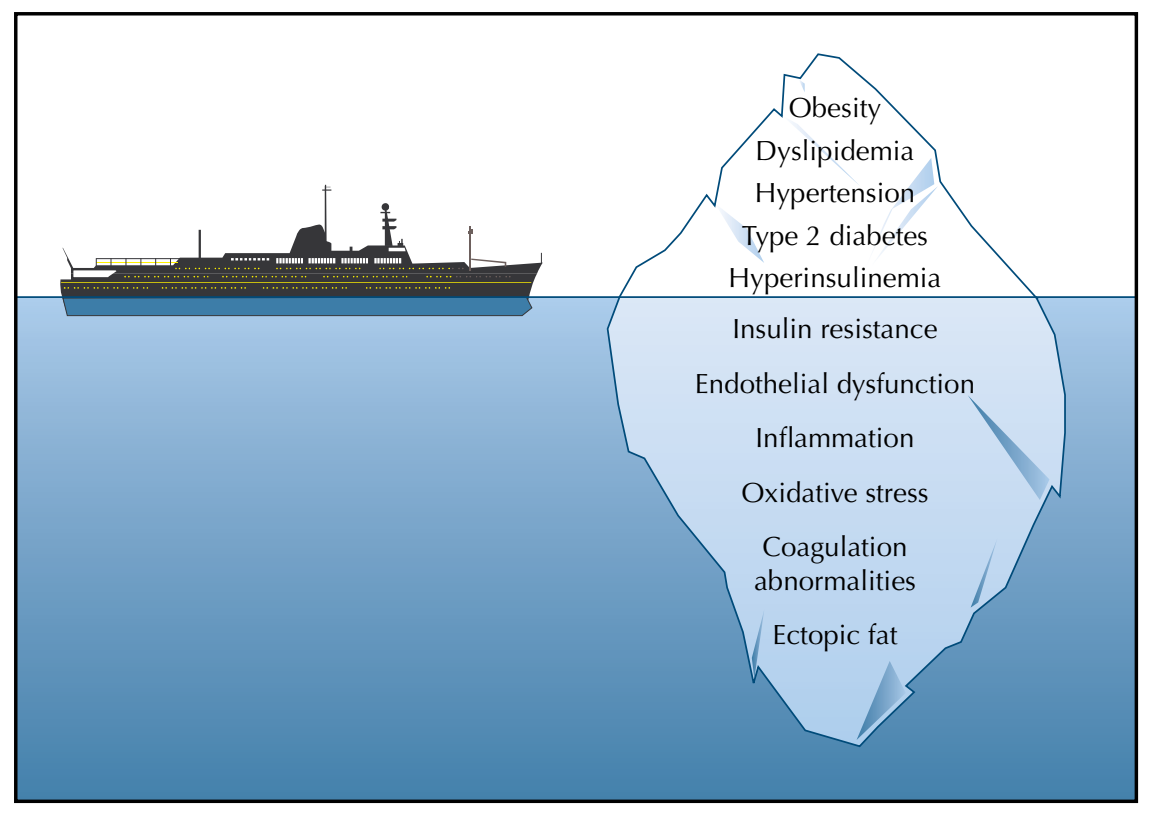

Figure 2. Metaphor of the metabolic syndrome.

surface" (Fig. 2). Awareness of the underlying disorders is important for understanding the pathophysiology and thus coherent treatment: be aware of insulin resistance and the associated (non-) traditional risk factors.

According to current guidelines for cardiovascular risk management, the presence of the metabolic syndrome may give direction to treatment $[65 \bullet \bullet]$. Identification of the metabolic syndrome not only has (therapeutic) consequences for the individual patient but can also have major effects for public health care in terms of (future) costs and use of health care resources. Therefore, it is of great importance to have a diagnosis based on well-established diagnostic criteria that allows reliable estimation of risk.

\section{Conclusions}

Currently, a critical discussion is ongoing concerning the role of the metabolic syndrome in (cardiovascular) risk prediction. From a clinical standpoint, presence of the metabolic syndrome identifies a person at increased risk for CVD and/or type 2 diabetes. Eventually, a better understanding of the specific cause(s) of the syndrome may contribute to improved risk estimation for the development of CVD and/or type 2 diabetes and may lead to better treatment of risk factors. The individual components (ie, dyslipidemia and hypertension) that make up the syndrome should be treated together. However, there are other risk factors, such as the direct vascular effects of insulin resistance and obesity. Awareness of the underlying disorders is important for understanding the pathophysiology and thus coherent treatment: be aware of insulin resistance and its associated (non-) traditional risk factors such as endothelial dysfunction and inflammation.

\section{References and Recommended Reading}

Papers of particular interest, published recently, have been highlighted as:

- Of importance

-. Of major importance

1. Stevens RJ, Coleman RL, Adler AI, et al.: Risk factors for myocardial infarction case fatality and stroke case fatality in type 2 diabetes: UKPDS 66. Diabetes Care 2004, 27:201-207.

2. Turner RC: The U.K. Prospective Diabetes Study. A review. Diabetes Care 1998, 21(suppl 3):C35-C38.

3. Caballero AE: Metabolic and vascular abnormalities in subjects at risk for type 2 diabetes: the early start of a dangerous situation. Arch Med Res 2005, 36:241-249.

4.• Gerstein HC, Yusuf S, Bosch J, et al.: Effect of rosiglitazone on the frequency of diabetes in patients with impaired glucose tolerance or impaired fasting glucose: a randomised controlled trial. Lancet 2006, 368:1096-1105.

The first evidence of useful treatment of patients at risk for diabetes.

5. Haffner SM, Stern MP, Hazuda HP, et al.: Cardiovascular risk factors in confirmed prediabetic individuals. Does the clock for coronary heart disease start ticking before the onset of clinical diabetes? JAMA 1990, 263:2893-2898.

6. Alberti KG, Zimmet PZ: Definition, diagnosis and classification of diabetes mellitus and its complications. Part 1: diagnosis and classification of diabetes mellitus provisional report of a WHO consultation. Diabet Med 1998, 15:539-553.

7. Balkau B, Charles MA: Comment on the provisional report from the WHO consultation. European Group for the Study of Insulin Resistance (EGIR). Diabet Med 1999, 16:442-443.

8. Executive Summary of The Third Report of The National Cholesterol Education Program (NCEP) Expert Panel on Detection, Evaluation, And Treatment of High Blood Cholesterol In Adults (Adult Treatment Panel III) [no authors listed]. JAMA 2001, 285:2486-2497.

9. Einhorn D, Reaven GM, Cobin RH, et al.: American College of Endocrinology position statement on the insulin resistance syndrome. Endocr Pract 2003, 9:237-252.

10. Alberti KG, Zimmet P, Shaw J: The metabolic syndrome-a new worldwide definition. Lancet 2005, 366:1059-1062. 
11. Ford ES, Giles WH, Dietz WH: Prevalence of the metabolic syndrome among US adults: findings from the third National Health and Nutrition Examination Survey. JAMA 2002, 287:356-359.

12. Panagiotakos DB, Pitsavos C, Chrysohoou C, et al.: Impact of lifestyle habits on the prevalence of the metabolic syndrome among Greek adults from the ATTICA study. Am Heart J 2004, 147:106-112.

13. Marques-Vidal P, Mazoyer E, Bongard V, et al.: Prevalence of insulin resistance syndrome in southwestern France and its relationship with inflammatory and hemostatic markers. Diabetes Care 2002, 25:1371-1377.

14. Gorter PM, Olijhoek JK, van der GY, et al.: Prevalence of the metabolic syndrome in patients with coronary heart disease, cerebrovascular disease, peripheral arterial disease or abdominal aortic aneurysm. Atherosclerosis 2004 , 173:363-369.

15. Hanley AJ, Karter AJ, Williams K, et al.: Prediction of type 2 diabetes mellitus with alternative definitions of the metabolic syndrome: the Insulin Resistance Atherosclerosis Study. Circulation 2005, 112:3713-3721.

16. Isomaa $\mathrm{B}$, Almgren $\mathrm{P}$, Tuomi $\mathrm{T}$, et al.: Cardiovascular morbidity and mortality associated with the metabolic syndrome. Diabetes Care 2001, 24:683-689.

17. Hu G, Qiao Q, Tuomilehto J, et al.: Prevalence of the metabolic syndrome and its relation to all-cause and cardiovascular mortality in nondiabetic European men and women. Arch Intern Med 2004, 164:1066-1076.

18. Lakka HM, Laaksonen DE, Lakka TA, et al.: The metabolic syndrome and total and cardiovascular disease mortality in middle-aged men. JAMA 2002, 288:2709-2716.

19. Ford ES: The metabolic syndrome and mortality from cardiovascular disease and all-causes: findings from the National Health and Nutrition Examination Survey II Mortality Study. Atherosclerosis 2004, 173:309-314.

20. Girman CJ, Rhodes T, Mercuri M, et al.: The metabolic syndrome and risk of major coronary events in the Scandinavian Simvastatin Survival Study $(4 S)$ and the Air Force/Texas Coronary Atherosclerosis Prevention Study (AFCAPS/TexCAPS). Am J Cardiol 2004, 93:136-141.

21. Hunt KJ, Resendez RG, Williams K, et al.: National Cholesterol Education Program versus World Health Organization metabolic syndrome in relation to all-cause and cardiovascular mortality in the San Antonio Heart Study. Circulation 2004, 110:1251-1257.

22. Malik S, Wong ND, Franklin SS, et al.: Impact of the metabolic syndrome on mortality from coronary heart disease, cardiovascular disease, and all causes in United States adults. Circulation 2004, 110:1245-1250.

23.• Dekker JM, Girman C, Rhodes T, et al.: Metabolic syndrome and 10-year cardiovascular disease risk in the Hoorn Study. Circulation 2005, 112:666-673.

A critically pointed study.

24. Bonora E, Kiechl S, Willeit J, et al.: Carotid atherosclerosis and coronary heart disease in the metabolic syndrome: prospective data from the Bruneck study. Diabetes Care 2003, 26:1251-1257.

25. Olijhoek JK, van der Graaf Y, Banga JD, et al.: The metabolic syndrome is associated with advanced vascular damage in patients with coronary heart disease, stroke, peripheral arterial disease or abdominal aortic aneurysm. Eur Heart J 2004, 25:342-348.

26. Schillaci G, Pirro M, Vaudo G, et al.: Metabolic syndrome is associated with aortic stiffness in untreated essential hypertension. Hypertension 2005, 45:1078-1082.

27.•• Saely CH, Koch L, Schmid F, et al.: Adult Treatment Panel III 2001 but not International Diabetes Federation 2005 criteria of the metabolic syndrome predict clinical cardiovascular events in subjects who underwent coronary angiography. Diabetes Care 2006, 29:901-907.

Obesity seems to not play the major role in the pathophysiology of the metabolic syndrome.
28. Mokdad AH, Bowman BA, Ford ES, et al.: The continuing epidemics of obesity and diabetes in the United States. JAMA 2001, 286:1195-1200.

29. Scuteri A, Najjar SS, Muller DC, et al.: Metabolic syndrome amplifies the age-associated increases in vascular thickness and stiffness. J Am Coll Cardiol 2004, 43:1388-1395.

There could be a higher risk than expected from the separate cardiovascular risk factors.

30. Wilson PW: Estimating cardiovascular disease risk and the metabolic syndrome: a Framingham view. Endocrinol Metab Clin North Am 2004, 33:467-481.

31. Reaven G: The metabolic syndrome or the insulin resistance syndrome? Different names, different concepts, and different goals. Endocrinol Metab Clin North Am 2004, 33:283-303.

32. Sakkinen PA, Wahl P, Cushman M, et al.: Clustering of procoagulation, inflammation, and fibrinolysis variables with metabolic factors in insulin resistance syndrome. $A m \mathrm{~J}$ Epidemiol 2000, 152:897-907.

33. Hulthe J, Bokemark L, Wikstrand J, Fagerberg B: The metabolic syndrome, LDL particle size, and atherosclerosis: the Atherosclerosis and Insulin Resistance (AIR) study. Arterioscler Thromb Vasc Biol 2000, 20:2140-2147.

34. Weyer C, Funahashi T, Tanaka S, et al.: Hypoadiponectinemia in obesity and type 2 diabetes: close association with insulin resistance and hyperinsulinemia. J Clin Endocrinol Metab 2001, 86:1930-1935.

35.• Yusuf S, Hawken S, Ounpuu S, et al.: Obesity and the risk of myocardial infarction in 27,000 participants from 52 countries: a case-control study. Lancet 2005, 366:1640-1649.

Obesity seems to play the major role in the pathophysiology of the metabolic syndrome.

36. Jazet IM, Pijl H, Meinders AE: Adipose tissue as an endocrine organ: impact on insulin resistance. Neth J Med 2003, 61:194-212.

37. Rebrin K, Steil GM, Getty L, Bergman RN: Free fatty acid as a link in the regulation of hepatic glucose output by peripheral insulin. Diabetes 1995, 44:1038-1045.

38. Boden G, Shulman GI: Free fatty acids in obesity and type 2 diabetes: defining their role in the development of insulin resistance and beta-cell dysfunction. Eur J Clin Invest 2002, 32(suppl 3):14-23.

39. Ginsberg HN, Huang LS: The insulin resistance syndrome: impact on lipoprotein metabolism and atherothrombosis. J Cardiovasc Risk 2000, 7:325-331.

40. Feinstein R, Kanety H, Papa MZ, et al.: Tumor necrosis factor-alpha suppresses insulin-induced tyrosine phosphorylation of insulin receptor and its substrates. $\mathrm{J} \mathrm{Biol} \mathrm{Chem}$ 1993, 268:26055-26058.

41. Ridker PM, Rifai N, Pfeffer M, et al.: Elevation of tumor necrosis factor-alpha and increased risk of recurrent coronary events after myocardial infarction. Circulation 2000, 101:2149-2153.

42. Martens FM, Rabelink TJ, op 't Roodt J, et al.: TNF-alpha induces endothelial dysfunction in diabetic adults, an effect reversible by the PPAR-gamma agonist pioglitazone. Eur Heart J 2006, 27:1605-1609.

43. Stefan N, Vozarova B, Funahashi T, et al.: Plasma adiponectin concentration is associated with skeletal muscle insulin receptor tyrosine phosphorylation, and low plasma concentration precedes a decrease in whole-body insulin sensitivity in humans. Diabetes 2002, 51:1884-1888.

44. Tschritter O, Fritsche A, Thamer C, et al.: Plasma adiponectin concentrations predict insulin sensitivity of both glucose and lipid metabolism. Diabetes 2003, 52:239-243.

45. Reaven GM, Lithell H, Landsberg L: Hypertension and associated metabolic abnormalities-the role of insulin resistance and the sympathoadrenal system. $N$ Engl J Med 1996, 334:374-381.

46. Steinberg HO, Baron AD: Vascular function, insulin resistance and fatty acids. Diabetologia 2002, 45:623-634. 
47. Wheatcroft SB, Williams IL, Shah AM, Kearney MT: Pathophysiological implications of insulin resistance on vascular endothelial function. Diabet Med 2003, 20:255-268.

48. Chait A, Brazg RL, Tribble DL, Krauss RM: Susceptibility of small, dense, low-density lipoproteins to oxidative modification in subjects with the atherogenic lipoprotein phenotype, pattern B. Am J Med 1993, 94:350-356.

49. Ashley FW Jr, Kannel WB: Relation of weight change to changes in atherogenic traits: the Framingham Study. J Chronic Dis 1974, 27:103-114.

50. Haffner SM, Ferrannini E, Hazuda HP, Stern MP: Clustering of cardiovascular risk factors in confirmed prehypertensive individuals. Hypertension 1992, 20:38-45.

51. Rocchini AP, Key J, Bondie D, et al.: The effect of weight loss on the sensitivity of blood pressure to sodium in obese adolescents. N Engl J Med 1989, 321:580-585.

52. Carretero OA, Oparil S: Essential hypertension. Part I: definition and etiology. Circulation 2000, 101:329-335.

53. Modan M, Halkin H, Almog S, et al.: Hyperinsulinemia. A link between hypertension obesity and glucose intolerance. J Clin Invest 1985, 75:809-817.

54. Falloon BJ, Heagerty AM: In vitro perfusion studies of human resistance artery function in essential hypertension. Hypertension 1994, 24:16-23.

55. Rizzoni D, Porteri E, Castellano M, et al.: Vascular hypertrophy and remodeling in secondary hypertension. Hypertension 1996, 28:785-790.

56. Fichtlscherer S, Rosenberger G, Walter DH, et al.: Elevated $\mathrm{C}$-reactive protein levels and impaired endothelial vasoreactivity in patients with coronary artery disease. Circulation 2000, 102:1000-1006.

57. Yudkin JS, Kumari M, Humphries SE, Mohamed-Ali V: Inflammation, obesity, stress and coronary heart disease: is interleukin-6 the link? Atherosclerosis 2000, 148:209-214.

58. Chia S, Qadan M, Newton R, et al.: Intra-arterial tumor necrosis factor-alpha impairs endothelium-dependent vasodilatation and stimulates local tissue plasminogen activator release in humans. Arterioscler Thromb Vasc Biol 2003, 23:695-701.
59. Ridker PM, Buring JE, Cook NR, Rifai N: C-reactive protein, the metabolic syndrome, and risk of incident cardiovascular events: an 8-year follow-up of 14719 initially healthy American women. Circulation 2003, 107:391-397.

60. Blake GJ, Ridker PM: C-reactive protein, subclinical atherosclerosis, and risk of cardiovascular events. Arterioscler Thromb Vasc Biol 2002, 22:1512-1513.

61. Kahn R, Buse J, Ferrannini E, Stern M: The metabolic syndrome: time for a critical appraisal: joint statement from the American Diabetes Association and the European Association for the Study of Diabetes. Diabetes Care 2005, 28:2289-2304.

62.• Deedwania P, Barter P, Carmena R, et al.: Reduction of low-density lipoprotein cholesterol in patients with coronary heart disease and metabolic syndrome: analysis of the Treating to New Targets study. Lancet 2006, 368:919-928. Evidence that patients with the metabolic syndrome are at high risk and can benefit from aggressive statin treatment.

63. Knowler WC, Barrett-Connor E, Fowler SE, et al.: Reduction in the incidence of type 2 diabetes with lifestyle intervention or metformin. N Engl J Med 2002, 346:393-403.

64. Tuomilehto J, Lindstrom J, Eriksson JG, et al.: Prevention of type 2 diabetes mellitus by changes in lifestyle among subjects with impaired glucose tolerance. $\mathrm{N} \mathrm{Engl} \mathrm{J} \mathrm{Med}$ 2001, 344:1343-1350.

65.• Grundy SM, Cleeman JI, Daniels SR, et al.: Diagnosis and management of the metabolic syndrome: an American Heart Association/National Heart, Lung, and Blood Institute Scientific Statement. Circulation 2005, 112:2735-2752. A very nice review about the metabolic syndrome at the moment. 